\title{
Virtual Education in English Literature Courses during Pandemic COVID-19: Merits and Demerits, and Needs
}

\author{
Azadeh Mehrpouyan (Corresponding author) \\ Department of English Literature, Velayat University, Iranshahr, Iran \\ Email: a.mehrpouyan@velayat.ac.ir \\ Elahesadat Zakeri \\ Faculty of Arts, Department of English, University of British Columbia, Canada
}

Received: 09/08/2021

Accepted: 12/11/2021

Published: 01/01/2022

Volume: 3 Issue: 1

How to cite this paper: Mehrpouyan, A., \& Zakeri, E. (2022). Virtual Education in English Literature Courses during Pandemic COVID-19: Merits and Demerits, and Needs. Journal of Critical Studies in Language and Literature, 3(1), 41-46

DOI: https://doi.org/10.46809/jcsll.v3i1.125

DOR: https://dorl.net/dor/20.1001.1.27324605.2022.3.1.5.2

This work is licensed under the Creative Commons Attribution International License (CC BY 4.0). http://creativecommons.org/licenses/by/4.0/

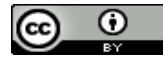

\begin{abstract}
Distance education and e-learning became widespread and necessary with the miracle of the internet and its increasing influence among the individuals much within the days of a pandemic outbreak of COVID-19. Many universities, institutions, and learners encourage using e-learning and begin growing in this field. This paper examines the merits and demerits of distance and online education teaching for English literature educators and students. Technology and increasing demand for education, traditional strategies do not meet the growing requirements of academic communities and virtual education and elearning with all their benefits and drawbacks attempt to meet these needs. This paper investigates e-teaching and e-learning infrastructure, needs, benefits, and limitations, in addition to opportunities and challenges of online education within the days of the coronavirus occurrence. The research method of the current study was conducted through a library study along with empirical study and descriptive analysis. New challenges of English literature educators and students in pandemic COVID-19 were identified and new approaches to remove the constraints are suggested. The results confirm online education is a constant educational need not limited to pandemic period and have to be compelled to develop productivity and creativity in learning with the appearance of recent technologies such as computers, the web, and social networks. These skills development can assist educators to find solutions for these difficulties in various areas of educational, cultural, and social issues. Blended learning can contribute to post-pandemic English literature classes and sustainable higher education.
\end{abstract}

Keywords: Virtual Education, E-Learning, Merits, Challenges, English Literature

\section{Introduction}

Although Millions of world populations died during the COVID-19 pandemic. Many countries of the world have set strict rules for the welfare, services, and daily activities of people so that they can reduce the number of their patients with less presence in different places to prevent the spread of the disease. However, some jobs cannot be closed/postponed to another time, one of which is education. Schools and universities cannot be closed with a disease that it is unclear how many years human beings will be able to overcome and have a certain safety. In the meantime, the only available solution is to use cyberspace and online education, which has been employed in all countries. Online and distance education these days involuntarily and compulsorily cover more than $90 \%$ of the world's education. Students, private and public academic and 
cultural centers/institutions all have no choice but to use this space for education. It should be stressed that if there was no cyberspace, all schools and universities would have been closed, and practical education and science would be closed in the whole world due to the spread of this virus, which shows the importance of cyberspace in development, progress, and prosperity. Cyberspace has also reached the people in shopping, ordering products, and banking has saved many for the people. Meanwhile, the lack of familiarity of the people, or in other words, the lack of media and virtual literacy, has caused the use of this tool to have problems for the users. However, Corona has created an opportunity for the governments to take serious steps to develop e-learning infrastructure and address other issues in this area, but there are a variety of views on the benefits and problems of e-learning (Schwartz, Wilson, Boden, Moore, Bradbury, \& Fletcher, 2020). The objectives of the present study are to examine e-teaching and e-learning merits, challenges, infrastructures, and needs of English literature educators and college students during the coronavirus outbreak. After identifying the challenges, some solutions and strategies are recommended. Since some basic and infrastructure problems emerged in online and distance education in many countries, the following issues are not only limited to English literature educators and students but other academics in other disciplines also experienced them. However, the researcher as an assistant professor in the English literature department evaluates the benefits and challenges of this type of education through the library and empirical study practically.

\section{Literature Review}

There are many research works, studies, and articles on e-learning and distance education in general and some examine specific subjects for example mathematics, statistics, language teaching merely, not language literature teaching but a few of them focus on literature; however, the present study investigates merits and demerits, and needs for online literature classrooms. Online instructional benefits discuss advantages in learning activities, course content, and student engagement in online courses (Bonk and Dennen, 2003). Posting self-introduction videos at the initial session of an online class can help contributors to have a better introductory experience that they recognize their classmates is an example of an instructional benefit without endangering any life with low costs. According to existing advantages and disadvantages of virtual education, instruction regularly adopted in online guides include (1) promotion interactivity through asynchronous and synchronous communication or delivery (Ku et al. 2011; Lawton et al., 2012); (2) facilitating using tools (Steinberg, 2010; Strang, 2012); (3) mistreatment video demonstrations e.g. screencasts for demonstrating tools, equipment and applications (Gemmell et al., 2011); and (4) switch a strong social presence or a way of belonging to a getting to know the community (Thomas et al., 2008; Zhang and Walls, 2006). According to Mukhtar et al. (2020), the advantages includesremote learning, comfort, accessibility, while the limitations involved inefficiency and difficulty in maintaining academic integrity. The recommendations were to train faculty on using online modalities and developing lesson plan with reduced cognitive load and increased interactivities. The coronavirus pandemic has forced students and educators across all levels of education to rapidly adapt to online learning. The impact of this - and the developments required to make it work - could permanently change how education is delivered (Lockee, 2021). Pandemic challenged the education system across the world and forced educators to shift to an online mode of teaching overnight (Dhawan, 2020).

Fearnley and Amora (2020) suggest that a learning management system can enrich instruction and acceptance of this learning technology by users is necessary its appropriate application in higher education but drawbacks should be identified and removed. The shortage of proper and deep interaction may be a common demerit in online courses because college students and instructors are placed in various geographical zones (Moore, 1991). This lack of interaction might actually lead to a way of isolation and frustration in online environments (Willging and Johnson, 2004).

Interaction allows college students in online classes to move and have cooperative learning. According to Moore (1989), three types of interaction in online courses are emerged: student-to-instructor, student-to-content, and student-to-student interaction. York et al. (2007) added student-instructor interaction refers to dialog and communication between students and instructor, the engagement of the students and the instructor is crucial within studying and instructing techniques. Studentcontent interaction refers to the extent of noticeable interaction taking place between the learners and the content (e.g., texts, audios, and videos). Student-student interaction refers to the dialog and exchanges between and/or among different contributors in a web course. Interaction is a vital issue in education based on e-learning.

In the mentioned interactions, two important aspects appear to consider first how and second how well the students receive and grasp the instruction and the learning materials in an online course (Bonk and Cunningham 1998). Davis and Snyder (2012) and Lawton et al. (2012) states motivating the students to interact with each other and the instructor guides them to show critical thinking and tools of online class may develop cognitive skills among the students. Using collaborative learning can help the students to perceive knowledge and reflect their perception and understanding if the instructor engages them in this way and use appropriate online teaching and learning strategies (Miller and Redman, 2010).

Maatuk et al. (2021) remark obstacles for example economic and technical support, on the job training, extended working conditions, technological skills, copyright rules, and expert improvement are constantly essential in applying e-learning in universities and college students accept it as true with that e-learning assists their learning. 


\section{Methodology}

Data were collected through literature review and empirical methods based on practical learning and teaching experiences within the seven online literature classes and students' reflections.(The average number of students in each class 25-35) The data analyzed based on descriptive-analysis method to cover the objectives of the study and respond to the following questions: what the merits and challenges of virtual education are for literature classrooms at universities during pandemic Covid-19 and what the needs and requirements for remove instructional and learning barriers as solutions for online English literature classes.

\section{Findings and Results}

E-learning is the use of information technology and computers to create learning experiences. E-learning includes a diverse range of information technology tools and due to the quantitative and qualitative growth and increase of Internet capabilities in recent years particularly during the pandemic. Nowadays, this type of learning is almost known as learning through the Internet. This method of learning itself possess advantages and disadvantages. It is noted that e-learning is associated with problems and usually software and computer experts have paced this field, and on the other hand, the role of educational designers is small. Further, some educators are unfamiliar with e-learning and the interaction and culture of elearning have developed compared to previous years, but it has not yet taken root in the community and bandwidth is a major problem in this regard. The instructors use e-learning, but the growth of e-learning in universities is far greater than its growth in organizational applications; while the global e-learning market is wider in this area. More attention is paid to the use of e-learning in states, universities, and academic centers. Institutions employ e-learning for different reasons; in general, it is possible to reduce costs, quickly introduce new products and services to the market, rapidly implement new information systems and business processes, efficient use of newly hired employees in the organization/institution, integrate employees nationally and globally and create a culture. The lack of hardware and strong servers, not paying attention to the issue of culture building, the unwillingness of users, and unpreparedness of the e-learning structure are examples of challenges in English literature classes during the pandemic. Many theories can support online classes for instance theories of cognition and learning which attempt to adapt to environments and spaces that are constantly changing. However, in some cases, because of the constant revisions, theories are relatively fragmented and complex that they may be unable to convey the subject of the matter that has arisen to define and explain (Mahmoudi \& Hashemikia, 2017). The actual experiences of online education during Pandemic COVID-19 revealed the following merits and challenges of English literature educators and students.

\subsection{Merits of Virtual education}

Virtual education possesses many benefits for learners and educators as follows. Noted these following experienced and practical merits of online English literature classes are not limited to these classes and the benefits can be generalized to some other academic disciplines as well.

- Being safe, even alive, and surviving during a pandemic (Mukhtar, Javed, Arooj, \& Sethi, 2020): Keeping individuals away safely from diseases is one of the most benefits of e-education. The world could understand the blessing of this factor perfectly during COVID-19.

- No need for physical presence and commutes (Dumford, 2018): In the virtual education model, such as teachers and students are connected using electronic platforms such as the Internet and video conferencing. It is unnecessary for the physical presence of teacher and student at the same time in a specific place. This eliminates the time and financial cost of travel and attendance for the student and the professor, and it makes students who are very busy able to use this training in their extra hours.

- Relatively lower cost (Gilbert, 2015): The cost of producing e-learning content is less than face-to-face instructional content; in addition, the audience of each session of the e-learning setting can be increased to reduce costs. After creating educational content, this content can be used several times and reduce costs. E-learning enables the use of educational content for more groups in the community.

- Adjust learning speed: In most informative e-learning models, educators can reduce or increase the speed of learning content and use its flexibility.

- Learning the required content: Learners in e-learning courses can focus on what they need and want to learn and avoid repeating what they know. With this point and considering that in virtual education, student-centered learning is the speed of learning increases even up to 50\%. Furthermore, the waste of time in e-learning courses is very low due to the lack of physical presence and travel.

- Visual and auditory appeal (Kumar, 2019): Most of the content of virtual education is created in new and attractive visual and visual methods, and no dullness and monotony of old books appear. This way increases the enthusiasm and energy of learners (particularly young and adolescent learners at colleges) and reduces the fatigue of excessive study.

- Up-to-date content: Electronic content is faster to deliver and produce than print and physical content, and new content can be delivered to learners very quickly. However, changing print educational content is difficult due to the high cost of producing and delivering content and this change is slow. This matter has led to the use of print and physical content for some areas where the educational content is constantly changing (such as software training programs). 
- Improving the quality of learning: The use of visual and multimedia content engages large parts of the learners' brain and helps the taught content to be recorded in their mind for a longer time, while the monotonous content is presented in textbooks and pamphlets. It is very volatile and is quickly erased from the mind of the students.

- Observance of educational justice: By using e-learning and reducing costs, as well as establishing the possibility of using education for users in remote and deprived areas, educational justice and equality is created.

- Using professors in different places: Since no need exists for the physical and permanent presence of professors in virtual education, professors present in many different places and universities can be used.

- Re-reading and re-reading: Each student can use and review the educational content as many times as she/he desires.

- Using the latest instructional methods: In virtual education, the most up-to-date teaching methods are always employed to convey content to the students, but classical education has often shown an inability to use new teaching methods.

- Possibility to use the content while traveling and working, etc.: To use the content of online education, the students do not need to be present in a certain place and they can attend the classroom from anywhere using a computer/mobile and the Internet. This makes learning possible for individuals who are constantly traveling.

- Using the best instructors: In face-to-face education, the instructor must be present in the classroom and therefore can cover a small and fixed number of students, and for this reason, many learners have the advantage of using strong and mature teachers. They stay educated and have to use weaker teachers. However, with virtual education, it is possible to use the best professors in each field for all learners particularly workshops. The learners can experience the best instructors, writers, and academic figures in these workshops.

- Possibility of on-the-job learning: For most on-the-job staff, education ends when they graduate from university and can no longer continue to learn while on the job. However, e-learning allows learners to learn even with the heaviest tasks.

- Increasing digital skills: since the students and educators need to handle many things online for example uploading and downloading, content creation, using audio and visual effects, compressor devices, file converters, finding and using useful apps, etc., they develop and improve their computer skills.

4.2. Challenges and Demerits of Virtual Education

We are currently facing the growing development of technology and the ever-expanding education, cannot ignore its present challenges. Problems and challenges of online education as infrastructure should be examined, addressed, and provided an appropriate platform to solve the problems at faculty stuructures. Based on the present empirical study in the English literature departments in one state university(Velayat University) and one private university(Tehran Azad University) in Iran, the general and major issues and challenges of the virtual education space are as follows:

- Low qualities of internet service and weak communication and technological infrastructure (Kyong-Jee, Shijuan, Curtis, Bonk, 2005; Jacob \& Radhai, 2016; Aboagye et al., 2020).

- Lack of computer equipment

- Weakness in technical support and organizing, controlling, and supervising them

- Lack of teaching methods arts in the virtual environment to the professors (Stewart,2008)

- Lack of study methods and skills in virtual education to students

- Failure to identify social and cultural harms of academics (including professors, students, and administrators)

- Failure to identify physical and psychological injuries of academics (including professors, students, and administrators)

- Lack of application of ergonomic principles in learning stations

- Lower academic competition in e-learning

- Unstandardized time and time span for different subjects in virtual education (applying the same standard time in traditional class for visual class)

- Not to consider the rate of teaching difficulty for professors in payment, bounce, teaching schedule, etc.

- Decreasing academic motivation

- Lack of collective participation in e-learning courses

- Fatigue during e-learning course

Identifying and solving these challenges affects the quality of faculty-student education and their interactions. The effectiveness of each is different, but in such a context, the desired quality of education and acceptable academic education can be achieved through considering the challenges and solving them. It is also required to notice the legal and ethical issues and the consequences of behavioral norms and the use of direct and indirect academic virtual networks as the second living space of the academic community for professional purposes. These issues even can affect the well-being of the individuals in the virtual education space. From a broader and deeper perspective, the role of the university community and the student population of the countries in the quality of e-education and cyberculture should not be underestimated.

\section{Needs and Solutions}

According to the identified challenges along with the merits of virtual education among English literature educators and students in pandemic COVID-19, the following necessities and solutions are recommended:

- Changing the organizational structure of universities: Certainly, when an education system changes, there is a need to redefine and transform the educational structure and evaluation of the university alongside the traditional structure. 
- Setting up specialized university virtual networks: Personal and common popular social networks are inappropriate for professional academic purposes.

- Improving university support infrastructure: some support infrastructures are essential to highlight for cyber education as follows.

- Build up communication infrastructure within the university

- Launch academic social networks

- Create academic messengers

- Maintain private sanctions against professors and students

- Prevent social harms

- Preserve indigenous culture

- Prevent isolation and depression, etc.

The learning environment is confused with individual social networks. Some students embroil the role of their professors and classmates as their followers and friends on social networks such as Instagram and so on. It is assumed wrongly that the professors/faculty members in non-university open space and outside of class time should be available 24 hours a day, 7 days a week, and at the service of questions and problems of academic, non-academic, technical, personal, and so on.

- Identifying the types of harms and consequences: In addition to the merits of e-learning like any other type of education, it possesses some demerits, challenges, and experienced/ possible harms which should be identified with the cooperation of sociologists, psychologists, educational and technology experts, Cyberspace police and other relevant scientific associations in the field of e-learning in order to protect academics against insults, defamation, threats, specific issues of virtual environments such as identity and privacy. After that, the causes of those harms should be investigated by setting up a strategic council and related working groups in the Ministry of Science and technology.

- Developing social and cultural skills in university cyberspace: Without the training and development of social skills and the culture of the university-specific cyberspace, academics will be harmed; hence, important actions must be taken to prevent undesired consequences.

- Monitoring and reviewing the advocacy of education status: To study the status of virtual education, its cyber-culture, empowerment, and awareness of the academic community in socio-cultural interactions of cyberspace (Bernard et al., 2009) and then prioritizing and classifying training courses related to basic cyber-culture can be accounted as the strategic measures.

\section{Conclusion}

This study explored the infrastructure, necessities, merits, and challenges of virtual education. New challenges and demerits of online English literature classes for educators and students during pandemic COVID-19 were explored and solutions were given accordingly. Since the basic problems appeared in higher education, the mentioned benefits and challenges are not restricted to online English literature courses. There are many serious fundamental problems commonly in distance education, which should be solved then might allow the researchers to study in detail for each subject. However, the results are reported and extracted from the experiences of English literature educators and students. The findings indicate online education possesses basic problems to have to be solved not only for English literature but other departments have also the same situation. Virtual education requires developing productivity and creativity in teaching and learning with the advent of new technologies such as digital devices and services, software, and apps, the Internet, social networks, etc., academics encounter new challenges in all areas of educational, technical, cultural, and social problems, which should take seriously in order to achieve a sustainable education system online.

\section{References}

Aboagye, E., Yawson, J. A., \& Appiah, K. N. (2020). COVID-19 and E-learning: The Challenges of Students in Tertiary Institutions. Social Education Research, 2(1), 1-8. https://doi.org/10.37256/ser.212021422.

Bernard RM, Abrami PC, Borokhovski E, Wade CA, Tamim RM, Surkes MA, et al. (2009). A meta-analysis of three types of interaction treatments in distance education. Rev Edu Res.79(3):1243-1289. doi:10.3102/0034654309333844.

Dhawan, S. (2020). Online Learning: A Panacea in the Time of COVID-19 Crisis. Journal of Educational Technology Systems, 49(1), 5-22. https://doi.org/10.1177/0047239520934018

Dumford, A.D. (2018). Miller, A.L. Online learning in higher education: exploring advantages and disadvantages for engagement. J Comput High Educ 30, 452-465 https://doi.org/10.1007/s12528-018-9179-z.

Gilbert, B. (2015). "Online Learning Revealing the Benefits and Challenges" Education Masters. Paper 303.

Jacob, S., \& Radhai, S. (2016). Trends in ICT e-learning: Challenges and expectations. International Journal of Innovative Research \& Development, 5(2), 196-201.

Kumar, SC. (2019). Awareness, benefits, and challenges of e-learning among the students of Kurukshetra University Kurukshetra: A study. Int J Inf Dissemination Tech. 8(4):227-230. doi:10.5958/2249-5576.2018.00048.1. 
Kyong-Jee Kim, Shijuan Liu, Curtis J. Bonk, (2005). Online MBA students' perceptions of online learning: Benefits, challenges, and suggestions, The Internet and Higher Education, Volume 8, Issue 4, https://doi.org/10.1016/j.iheduc.2005.09.005.

Lockee, B.B. Online education in the post-COVID era. Nat Electron 4, 5-6 (2021). https://doi.org/10.1038/s41928-020$\underline{00534-0}$

Maatuk, A.M., Elberkawi, E.K., Aljawarneh, S. et al. (2021). The COVID-19 pandemic and E-learning: challenges and opportunities from the perspective of students and instructors. J Comput High Educ https://doi.org/10.1007/s12528021-09274-2

Mahmoudi, M., Hashemi Kia,A. (2017). Explore the advantages, disadvantages, and challenges of e-learning, Second National Congress on Transformation and Innovation in the Humanities.

Mukhtar, K., Javed, K., Arooj, M., \& Sethi, A. (2020). Advantages, Limitations, and Recommendations for online learning during COVID-19 pandemic era. Pakistan journal of medical sciences,36(COVID19-S4), S27-S31. https://doi.org/10.12669/pjms.36.COVID19-S4.2785

Mukhtar, K., Javed, K., Arooj, M., \& Sethi, A. (2020). Advantages, Limitations and Recommendations for online learning during COVID-19 pandemic era. Pakistan journal of medical sciences,36(COVID19-S4), S27-S31. https://doi.org/10.12669/pjms.36.COVID19-S4.2785

Schwartz AM, Wilson JM, Boden SD, Moore TJ, Jr, Bradbury TL, Jr, Fletcher ND. (2020). Managing Resident Workforce and Education During the COVID-19 Pandemic: Evolving Strategies and Lessons Learned. JBJS Open Access.5(2):e0045. doi:10.2106/JBJS.OA.20.00045.

Stewart D. (2008). Classroom management in the online environment. J Online Learn Teach. 4(3):371-374. 